\title{
Estudo do comportamento do revestimento de pavimento utilizando mistura asfáltica morna com adição de borracha moída de pneu na SPA-248/055
}

\author{
Cecília Fortes Merighi ${ }^{1}$, Carlos Yukio Suzuki ${ }^{2}$
}

${ }^{1}$ Escola Politécnica da Universidade de São Paulo, ce.cissa@gmail.com

2Escola Politécnica da Universidade de São Paulo, carlos.suzuki@planservi.com.br

\section{Recebido:}

28 de dezembro de 2015

Aceito para publicação:

30 de agosto de 2017

Publicado:

30 de dezembro de 2017

Editor de área:

Jorge Barbosa Soares

\section{Palavras-chaves:}

Mistura asfáltica morna,

Ligante-borracha,

Redução de emissão de poluentes,

Desempenho pavimento.

\section{Keywords:}

Warm mix asphalt,

Rubberized binder,

Pollutants emission reduction,

Pavement performance.

DOI:10.14295/transportes.v25i4.1055

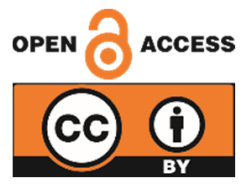

\begin{abstract}
RESUMO
Este artigo apresenta um estudo realizado com mistura asfáltica morna utilizando ligante aditivado com agente surfactante e borracha moída de pneus. Foram feitos ensaios para verificar o comportamento mecânico de mistura de concreto asfáltico com asfalto-borracha morno e foi comparado com uma mistura de referência, de concreto asfáltico com asfalto-borracha usinado a quente. A primeira apresentou resultado satisfatório, dentro dos limites de norma. Adicionalmente, realizou-se a análise das emissões de poluentes, no momento da produção das duas misturas. Os resultados indicaram que houve redução de poluentes como fumos totais, fumos solúveis e compostos orgânicos voláteis (VOCs). Por fim, foi avaliado o trecho experimental, executado na SPA-248/055, Pista Oeste e comparado ao trecho de referência, localizado na mesma rodovia. Os resultados obtidos mostram o desempenho positivo da mistura asfáltica morna, quando comparado ao pavimento do trecho de referência, ao longo de quatro anos de observação.
\end{abstract}

\begin{abstract}
This paper presents a study of a warm asphalt mix using rubberized binder additive with surfactant. Tests were made to verify the mechanical behavior of the warm mixture and then compared to a reference rubberized hot mixture. The warm asphalt mix presented satisfactory results. Also, it was made an analysis of reducing pollutant emissions during the mix production. A test section was performed with the warm mixture, located in SPA-248/055, West Lane and compared to the hot mix reference section, located on the same highway. The results indicated that there is a reduction of pollutants such as total smoke, fumes soluble and volatile organic compounds (VOCs). Both the experimental and the reference section were evaluated during 4 years for pavement performance parameters. The results showed a positive behavior of warm asphalt mix compared to the reference pavement section.
\end{abstract}

\section{INTRODUÇÃO}

A tecnologia emergente de mistura asfáltica morna permite reduzir a temperatura na produção da mistura asfáltica e, consequentemente, na aplicação em pista. Define-se misturas asfálticas mornas como um material que essencialmente tem a mesma mistura volumétrica e propriedades de desempenho que as misturas convencionais a quente (HARRIGAN, 2012). Enquanto que a mistura convencional é produzida em temperaturas variando de $140^{\circ} \mathrm{C}$ a $160^{\circ} \mathrm{C}$, a mistura asfáltica morna é usinada entre $100^{\circ} \mathrm{C}$ e $140^{\circ} \mathrm{C}$ (PROWELL; HURLEY; FRANK, 2012).

A mistura morna proporciona diversos benefícios, entre eles (PROWELL; HURLEY; FRANK, 2012):

a) Qualidade na compactação da mistura em ambientes frios: 0 aditivo permite a pavimentação em 
lugares frios, inferiores a $10^{\circ} \mathrm{C}$, que é a temperatura ambiente mínima para misturas modificadas com borracha moída de pneu (DNIT 112/2009 - ES), uma vez que oferece, ainda, trabalhabilidade à massa asfáltica. Esta condição, em misturas a quente com asfalto-borracha, não é observada;

b) Possibilita o aumento da distância de transporte ou à frente de serviço mantendo boa trabalhabilidade e compactação da massa asfáltica, uma vez que o aditivo de mistura morna diminui a viscosidade do ligante asfáltico, permitindo maior trabalhabilidade em temperaturas mais baixas;

c) Redução de combustível: com a usinagem em temperaturas menores, o consumo de energia é menor. Motta (2011) obteve a redução de 15\% com a redução de temperatura de secagem durante a usinagem da mistura asfáltica morna;

d) Diminuição de emissões de agentes nocivos na usina e no campo: investigações realizadas em usinas de asfalto americanas concluíram que quando a temperatura de produção reduz de $29^{\circ} \mathrm{C}$ a $43^{\circ} \mathrm{C}$, a quantidade de materiais particulados cai entre $67 \%$ e $77 \%$, enquanto o fumo do asfalto, de $72 \%$ a $81 \%$, comparados com uma mistura de referência (SABITA, 2011).

Cabe mencionar que o fumo de asfalto pode ser dividido em duas frações: a fração partícula, que é formada de compostos orgânicos solúveis em benzeno, de onde surgem os hidrocarbonetos policíclicos aromáticos (HPA) particulados; e de fração gasosa, onde são obtidos os compostos orgânicos voláteis e semi-voláteis, ou seja, HPAs gasosos (GAUDEFROY; VIRANAIKEN; PARANHOS, 2008). Os trabalhadores expostos aos fumos de asfalto são sujeitos a problemas de saúde respiratória e irritações oculares (THE ASPHALT ROOFING INDUSTRY SCIENCE \& MEDICAL GROUP, 2000).

A diminuição da temperatura de usinagem e, consequentemente, das emissões destes agentes é de suma importância para a saúde do trabalhador e conservação do meio ambiente. Inclusive, Rubio et al. (2013) afirmam que a verificação do nível de emissão de poluente na pavimentação é tão importante que na Espanha, a regulação requer que as companhias de asfalto realizem medidas periódicas dos gases de combustão e partículas em suspensão.

Motta (2011) se propôs a avaliar a redução de emissões de poluente, especialmente HPAs relativos ao material particulado durante a usinagem, no momento do carregamento do caminhão na usina e por fim, no lançamento do material em pista nas misturas utilizando asfalto-borracha e CAP 30/45. 0 resultado obtido pela autora indicou redução em cerca de três vezes da concentração total de HPAs relativos ao material particulado dos ambientes de mistura morna, em relação àquela a quente.

São vários os tipos de aditivos para mistura morna existentes no mercado, variando de produtos químicos surfactantes a ceras orgânicas e podem ser adicionados no concreto asfáltico que contém asfaltoborracha.

0 ligante modificado com borracha permite aumentar a resistência à deformação permanente e ao trincamento por fadiga, podendo ainda prolongar a vida do pavimento (RODRÍGUEZ-ALLOZA et al., 2014). No entanto, a incorporação da borracha aumenta a viscosidade do ligante (BAHIA; DAVIS, 1994; BERNUCCI et al., 2010; RODRÍGUEZ-ALLOZA et al., 2014) além de demandar maior temperatura de usinagem e compactação (RODRÍGUEZ-ALLOZA et al., 2014).

O componente fluidificante presente nos aditivos para misturas mornas permite reduzir a viscosidade do ligante-borracha (RODRÍGUEZ-ALLOZA et al., 2014), dando mais trabalhabilidade à mistura asfáltica, sem afetar o desempenho do pavimento (YU; LENG; WEI, 2014; RODRÍGUEZ-ALLOZA et al., 2014). Yu, Leng e Wei (2014) também verificaram que com esta adição, foi possível usinar e compactar misturas com borracha em temperaturas menores.

Dentro do contexto exposto, os objetivos deste trabalho são (i) acompanhar a aplicação da mistura asfáltica morna com ligante-borracha em campo na rodovia de acesso SPA-248/055, (ii) verificar os parâmetros sustentáveis, como a redução de emissão de poluente e consumo de combustível durante a usinagem e (iii) avaliar o seu comportamento em comparação com a mistura de referência, ao longo de 4 anos de serviço. 


\section{DESENVOLVIMENTO DA PESQUISA}

Foram estudadas duas misturas asfálticas, ambas aditivadas com $15 \%$ de borracha moída de pneu. A primeira, denominada BWMA, era uma mistura asfáltica morna, e a segunda uma mistura a quente de referência, denominada AB. Na mistura BWMA foi adicionado 0,4\% de agente surfactante Evotherm por peso de ligante no terminal da distribuidora de asfalto, conforme especificado pelo fabricante. A utilização de uma porcentagem menor não permitiria trabalhar em temperaturas menores, agiria apenas como um melhorador de viscosidade.

No estudo laboratorial, as misturas foram dosadas através do método Marshall. Durante a usinagem, amostras foram recolhidas para ensaios de resistência à tração por compressão diametral, estabilidade e verificação volumétrica. A investigação de redução da emissão de poluentes e consumo de combustível foi realizado na usinagem da massa asfáltica.

Na obra observaram-se as temperaturas de usinagem, chegada da mistura em campo e espalhamento. Após a compactação, a deflexão, a irregularidade longitudinal e o grau de compactação foram verificados em pista.

A mistura granulométrica seguiu a faixa de trabalho da mistura descontínua densa tipo "Gap Graded" faixa D do Departamento de Transporte da Califórnia (California Department of Transportation - Caltrans), conforme a Figura 1.

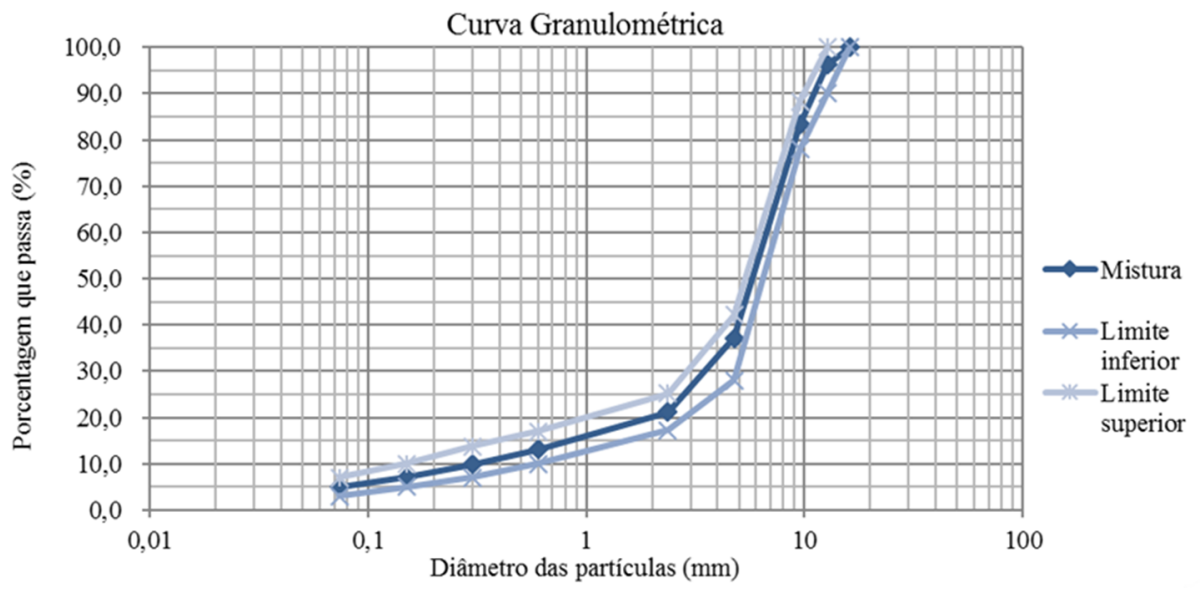

Figura 1. Curva granulométrica da mistura asfáltica descontínua densa "Gap Graded" Caltrans - faixa D.

Para ambas as misturas, a dosagem Marshall estabeleceu teor ótimo 6\% de ligante asfáltico, para um volume de vazios de $5 \%$.

Os agregados utilizados nas misturas, de origem granítica, eram provenientes da Pedreira Embu Itapeti (SP). Adicionalmente, empregou-se $2 \%$ de cal hidratada, a fim de melhorar a adesividade do ligante asfáltico.

\section{TRECHO EXPERIMENTAL: APLICAÇÃO, CONTROLE, VERIFICAÇÃO DA REDUÇÃO DE POLUENTES}

0 trecho experimental com mistura BWMA foi realizado na rodovia de acesso SPA 248/055 (Rodovia Cônego Domenico Rangoni), entre os quilômetros 3+000 e 6+000 da Pista Oeste, em toda a seção. A mistura $A B$ foi aplicada no trecho entre os quilômetros $1+000$ e 3+000. A execução de ambos os trechos ocorreu em 2012.

O projeto de restauração foi realizado devido a obrigações contratuais, uma vez que se trata de uma via concessionada. A rodovia, com volume diário médio (VDM) de 5237 (ECOVIAS, 2008), em geral apresentava boas condições superficiais e de conforto da superfície do pavimento. 0 projeto, com período de 8 anos, previa reparos localizados e aplicação de $3 \mathrm{~cm}$ de camada de revestimento asfáltico. 
A usina de asfalto utilizada foi a da Ecovias, que é do tipo gravimétrica - UAB 18 Advanced, com pugmill de eixo duplo e é movida a gás liquefeito de petróleo (GLP), com capacidade de produção de 100 a 140 ton./hora.

Durante a usinagem, não se observaram problemas ou pontos de atenção como aconteceu em 2011, quando a Ecovias aplicou a mistura asfáltica morna com asfalto-borracha e observou, na época, a ocorrência de problemas de maior corrente (Amperes) durante os processos de mistura, levando a um pico de sobrecarga dos disjuntores, como citado por MERIGHI et al., 2012. Os autores constataram que a origem do problema foi na temperatura de usinagem dos agregados, que quanto menor, maior a corrente (A) dos motores do misturador.

Na usinagem da mistura BWMA, o agregado foi aquecido em temperatura inferior ( $135^{\circ} \mathrm{C}$ ), enquanto que o ligante foi inserido em uma temperatura de aproximadamente $175^{\circ} \mathrm{C}$. Já em campo, assim como esperado, as temperaturas de trabalho são menores que as de usina, como mostra a Tabela 1 . As temperaturas de usinagem e aplicação da mistura $A B$ são usuais à equipe de pavimentação da Ecovias, enquanto que a temperatura de usinagem da mistura BWMA foi definida pelo fornecedor do aditivo surfactante.

Tabela 1: Temperaturas médias

\begin{tabular}{lll}
\hline Temperatura $\left({ }^{\circ} \mathbf{C}\right)$ & AB & BWMA \\
\hline Temperatura de usina & 165 & $135-150$ \\
Temperatura de aplicação em pista & 155 & $120-135$ \\
\hline Fonte: Merighi (2014) & &
\end{tabular}

A compactação foi obtida, para os dois trechos, com dois rolos tipo chapa de 11 toneladas. Durante a compactação, no total foram cinco passadas de rolo em vibração, para obter grau de compactação (GC) maior que 97\%, conforme especificado pela norma DNIT 112/2009 - ES. Para melhor acabamento foi usada vibração somente nas juntas.

Entre os quilômetros 4 e 5 foram retirados 11 corpos-de-prova e todos apresentaram grau de compactação acima de 97\%, comprovando que mesmo a mistura asfáltica morna sendo compactada a temperaturas bem menores que a mistura de referência, esta atingiu GC satisfatório e atendeu a norma DNIT 112/2009-ES.

\subsection{Resistência à tração por compressão diametral}

Foram coletadas amostras para a determinação da resistência à tração por compressão diametral (RT), seguindo a norma ABNT NBR 15087, durante a produção da mistura e compactadas sem a necessidade de reaquecimento. Os valores médios dos 15 corpos de prova da mistura BWMA e 12 da mistura $A B$ são exibidos na Tabela 2, onde observa-se que o resultado obtido para a mistura $A B$ é maior que para a BWMA.

Tabela 2: Resultados resistência à tração por compressão diametral e volume de vazios (Vv)

\begin{tabular}{llll}
\hline Ensaio & BWMA & AB & Mínimo (DNIT 112/2009 - ES) \\
\hline $\mathrm{RT}( \pm$ desv. padrão) [MPa] & $1,08( \pm 0,03)$ & $1,12( \pm 0,02)$ & 0,50 \\
$\mathrm{VV}( \pm$ desv. padrão) $[\%]$ & $5,4( \pm 0,2)$ & $5,0( \pm 0,1)$ & $4-6$ \\
\hline Fonte: Adaptado de Merighi $(2014)$ &
\end{tabular}

A análise estatística foi conduzida com a utilização do programa R-project versão 3.2.5. Com a finalidade de avaliar se os valores médios obtidos diferiam, foi utilizado o teste estatístico não paramétrico de Wilcoxon. A Figura 2a mostra o gráfico tipo box-plot comparando as duas médias. 0 teste estatístico obteve valor -P de 0, 0005495, para um nível de confiança de 99\%.

A hipótese nula era que as médias seriam iguais. Portanto, para este grau de confiança, os resultados não são aderentes, ou seja, apesar de apresentarem valores muito próximos, não são iguais. Motta (2011) também observou que a resistência à tração da mistura asfáltica morna era inferior à da mistura de referência, usinada a quente. 


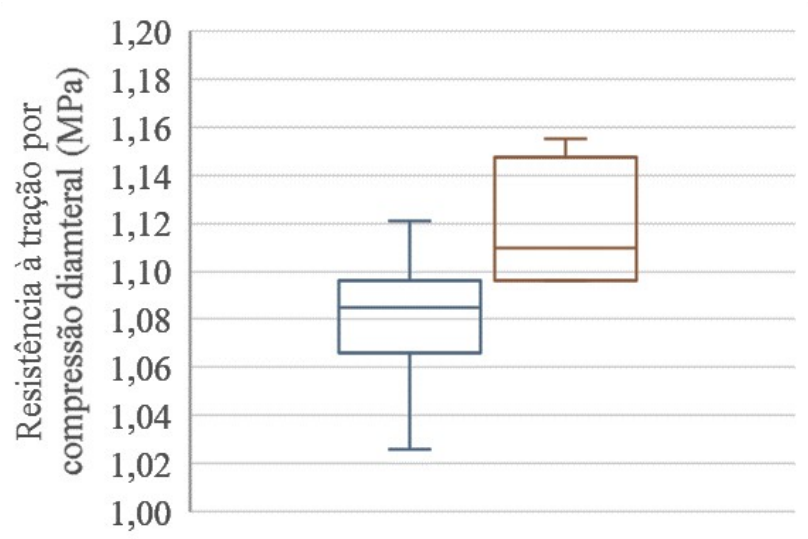

$\square \mathrm{BWMA} \square \mathrm{AB}$

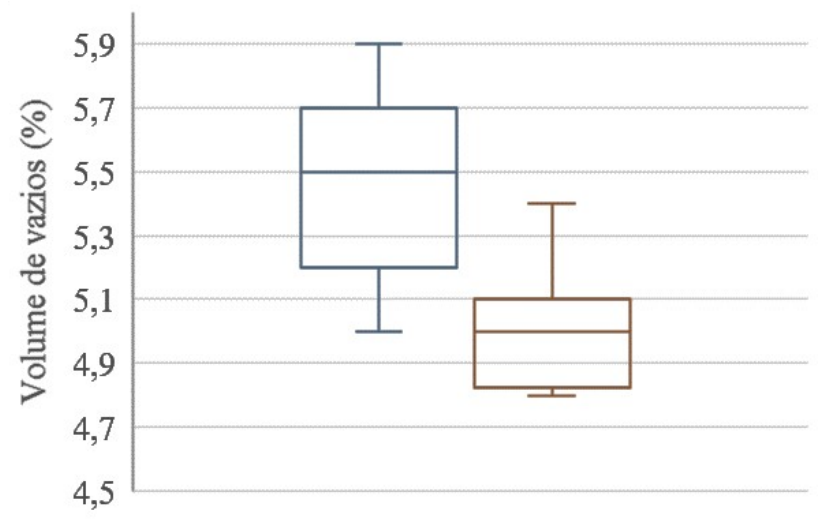

$\square$ BWMA $\square \mathrm{AB}$

Figura 2. (a) Box-plot das resistências médias à tração por compressão diametral das misturas BWMA e $A B$ (b) Diagrama de caixas do ensaio de volume de vazios das misturas BWMA e AB. Fonte: Merighi (2014)

O volume de vazios obtidos destes corpos de prova apresentou-se dentro do limite exigido para a mistura asfáltica descontínua Gap Graded com faixa granulométrica D da Caltrans, que varia entre 4 a $6 \%$. No entanto, na Figura 2b, mostra que o valor -P também foi inferior ao $\alpha$ adotado, resultando em 0,0002807, logo, os valores de volumes de vazios das amostras AB e BWMA não são aderentes.

Uma das prováveis causas desta pequena diferença é a temperatura de compactação. Ambas as misturas atendem os limites de volume de vazios da faixa Gap Graded D, no entanto, a mistura AB, que foi compactada, em laboratório, em temperatura maior, apresenta volume de vazios menor que o da mistura BWMA.

É interessante apontar para as relações entre resistência à tração e volume de vazios apresentados nas Figuras $2 \mathrm{a}$ e $2 \mathrm{~b}$, que se nota que quanto menor o volume de vazios, maior a resistência à tração da mistura asfáltica, uma vez que em ambos os parâmetros estão intrinsicamente relacionados.

\subsection{Controle de temperatura}

O controle de temperatura da mistura foi realizado no descarregamento da massa asfáltica no caminhão basculante e durante sua compactação, após a mistura percorrer uma distância de 70 quilômetros, entre a usina e o local de aplicação. 0 controle tecnológico permitiu rastrear o gradiente térmico e comparar as misturas, verificando se realmente existe o benefício de possibilitar aumento da frente de trabalho e menor perda de temperatura da mistura asfáltica morna.

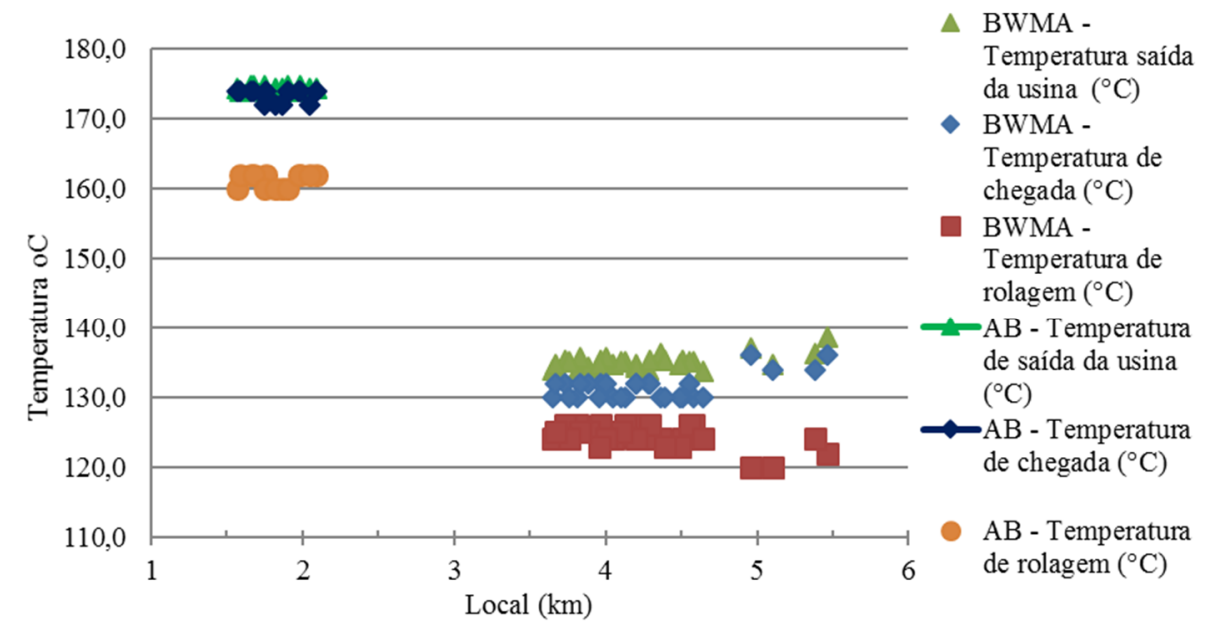

Figura 3. Temperaturas da mistura $A B$ e BWMA. 
A Figura 3 exibe os resultados do controle de temperaturas efetuado com a mistura BWMA e AB. Para os dois trechos, o local de aplicação apresentava céu aberto e temperatura média de 15ㄷ․ A perda de temperatura na rolagem da massa foi, na média, de 5,5\% para a mistura BWMA e 7\% para a AB, sendo estes valores muito próximos.

\subsection{Análise de emissões}

Para a análise das emissões foram realizadas avaliações em torno do caminhão basculante, na usina, utilizando métodos de higiene ocupacional; sendo os testes e laudo realizados pela empresa Environ. Realizou-se a medição de Fumos de Asfalto (HPAs em fração solúvel em Benzeno e particulado total), além dos compostos orgânicos voláteis (VOCs), como o n-Hexano na usina de asfalto. Estes compostos foram escolhidos pois representam um conjunto de poluentes que indicam a qualidade do ar, além se serem nocivos à saúde humana, causando males respiratórios e em casos extremos até câncer (NIOSH, 2000).

A metodologia utilizada para a amostragem da emissão de fumos de asfalto (fração solúvel em benzeno e particulado total) foi o MDHS 14/3 e NIOSH 5042 para análise gravimétrica. Foi empregado filtro de fibra de vidro com porosidade de $1 \mu \mathrm{m}$ e diâmetro de $25 \mathrm{~mm}$ e amostrador com vazão de 2,0 $\pm 0,1$ l/min. Em uma mesma amostra foram determinados particulado total, fração solúvel e HPAs.

Para a determinação de VOCs aplicou-se o método NIOSH 1500 - Cromatografia de gás com detector de ionização de chama, utilizando um amostrador tipo tubo de carvão ativo de 400/200 mg e vazão de amostragem de $0,05 \mathrm{l} / \mathrm{min}$. 0 solvente usado no ensaio foi o dissulfeto de carbono.

Para cada mistura foram dois dias de medição para a análise de emissão, caso fosse necessário descartar algum dado. No entanto, para o estudo foi descartado o primeiro dia da mistura AB, pois os filtros ficaram saturados, comprometendo os resultados do dia, mas não o resultado final. No segundo dia, foram utilizados dois conjuntos de filtros e coletou-se as emissões provenientes do carregamento de 7 caminhões. Para a BWMA, no primeiro dia foram verificados 5 caminhões com dois conjuntos de filtros e no segundo, 4 caminhões, com um único conjunto de filtros.

Na usina foram realizadas 5 coletas simultâneas, sendo quatro medidores posicionados próximos à caçamba do caminhão basculante, circundando-o, e o quinto próximo ao local onde o operador da usina fica. Durante a realização do ensaio, cada caminhão demorou 15 minutos para ser carregado. As Figuras 4a e 4b mostram, respectivamente, o tipo de medidor utilizado durante as amostragens e a localização dos mesmos ao redor do caminhão basculante.
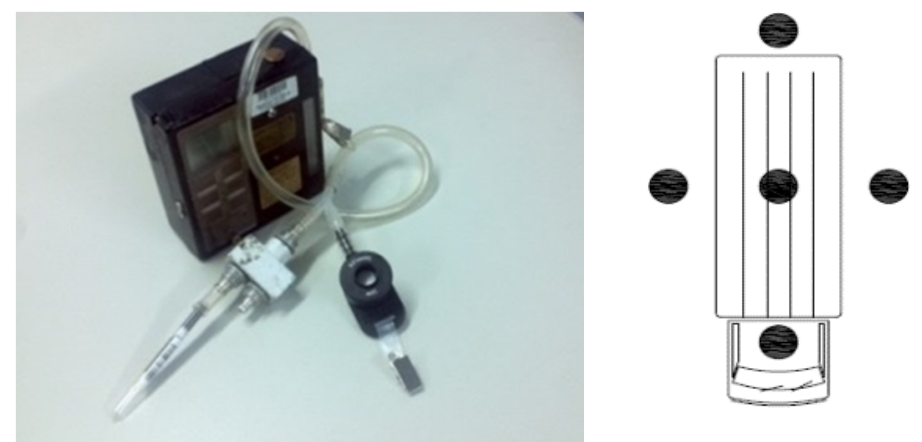

Figura 4. (a) Medidor para leitura de emissões de poluentes (b) Esquema do posicionamento dos medidores ao redor do caminhão basculante. Fonte: Merighi (2014)

Tomou-se o cuidado de se ponderar as variáveis que podem afetar os resultados como condições climáticas, principalmente velocidade e direção dos ventos, assim, nas medições das misturas BWMA e AB, a temperatura ambiente e as condições climáticas foram similares: dia ensolarado e temperatura média de $15^{\circ} \mathrm{C}$. 
Os valores obtidos nas medições simultâneas (em torno do caminhão) foram tratados, calculando-se a média ponderada das coletas, uma vez que cada conjunto de filtros mediu diferentes quantidades de caminhões (Tabela 3).

Tabela 3: Resultados das medições realizadas

\begin{tabular}{llll}
\hline Mistura & VOC (mg/ton.) & Fumos Solúveis (mg/ton.) & Fumos Totais (mg/ton.) \\
\hline AB & 1,036 & 1,599 & 17,797 \\
BWMA & 0,368 & 0,166 & 2,473 \\
\hline
\end{tabular}

Pode-se notar, através dos resultados obtidos, a redução de 64\% na emissão de compostos orgânicos voláteis (VOCs), 90\% nos fumos voláteis de asfalto e 86\% nos fumos totais.

\subsection{Redução no consumo de combustível fóssil}

Diariamente, durante a usinagem das misturas asfálticas, foi medido o nível do tanque de armazenamento de gás liquefeito de petróleo (GLP) no início da produção e no final, de modo que foi possível determinar o consumo médio de combustível.

A mistura $\mathrm{AB}$ consumiu em média 5,5 kg/ton., enquanto que a BWMA, 4,4 kg/ton. de GLP (MERIGHI, 2014). Comparando as duas taxas, verificou-se a redução de $20 \%$ do consumo de GLP na produção da mistura BWMA. Se o valor de compra do GLP é de R\$2,08/kg (outubro/2014), para uma produção diária de 700 ton., haveria economia de $\mathrm{R} \$ 1.600,00$, aproximadamente por dia.

No entanto, ressalta-se que o consumo de GLP pode variar, principalmente em função da mudança na umidade do agregado e do clima. No caso da pesquisa, a umidade máxima do agregado, para a Brita $3 / 4$ foi de $1 \%$ e da Brita $5 / 8$, de $2 \%$ e o material foi estocado em local coberto.

\section{MONITORAMENTO DO TRECHO}

Para a avaliação funcional do pavimento executaram-se, entre 2012 (antes da obra) e 2016, levantamentos de condição de superfície (DNIT 006/2003 PRO) e de irregularidade longitudinal de superfície (IRI), com a utilização do perfilômetro a laser (ASTM E950-98).

\subsection{Inventário de superfície do pavimento}

0 cadastro de defeitos na superfície do pavimento e o respectivo cálculo do Índice de Gravidade Global (IGG) foram realizados seguindo a norma DNIT 006/2003 PRO. A Figura 5 exibe os resultados do IGG da faixa 02, externa, mais carregada, obtidos em agosto de 2012 (antes da obra), e em março dos anos 2013 e 2015 (após a obra).

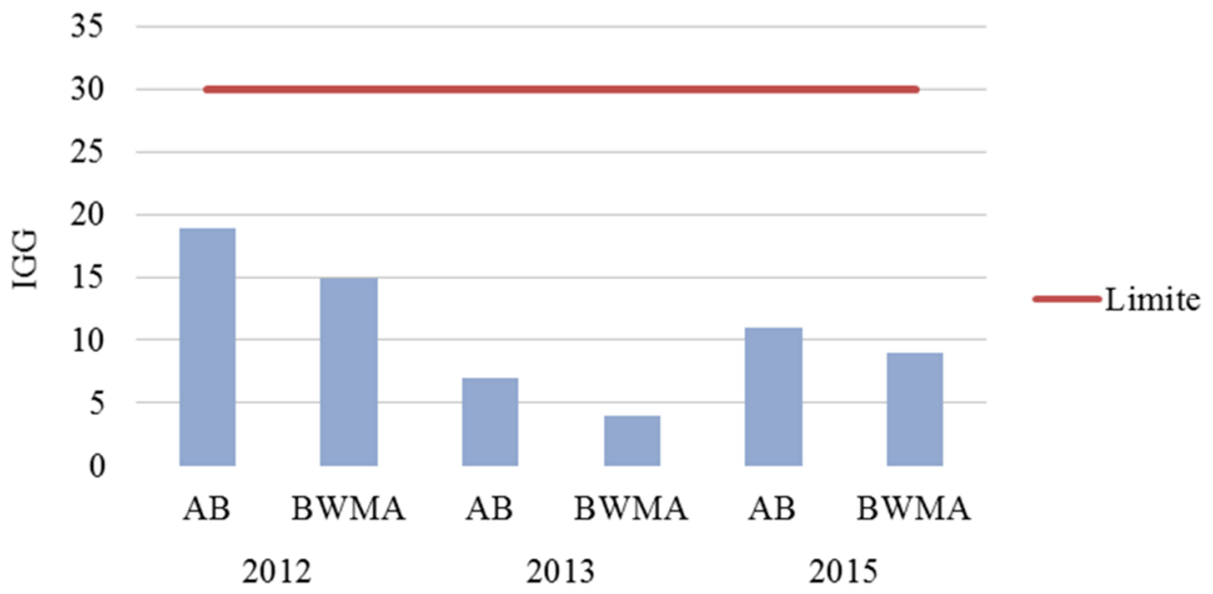

Figura 5. Índices de Gravidade Global dos anos 2012, 2013 e 2015 na faixa 02 
Na Figura 5 é observado que no trecho BWMA, o IGG não era elevado antes da obra, estando inclusive abaixo do limite máximo de 30, valor estipulado pela Agência de Transportes do Estado de São Paulo ARTESP. Como mencionado anteriormente, a obra foi realizada para atender às obrigações contratuais.

Pode-se notar que em 2013 houve melhoria no índice, como é esperado após uma obra de restauração. Em 2015, o IGG aumentou demonstrando comportamento estimado de uma rodovia solicitada pelo tráfego pesado e o período de projeto, que é de 8 anos. As duas misturas, obtiveram resultados satisfatórios no desempenho do IGG durante o período em que a mistura foi observada.

\section{2 Índice de irregularidade longitudinal}

A irregularidade longitudinal do pavimento foi levantada com perfilômetro a laser. A Figura 6 exibe os valores médios por quilômetro da faixa 02, também com valores obtidos em 2012, em 2013 a 2016.

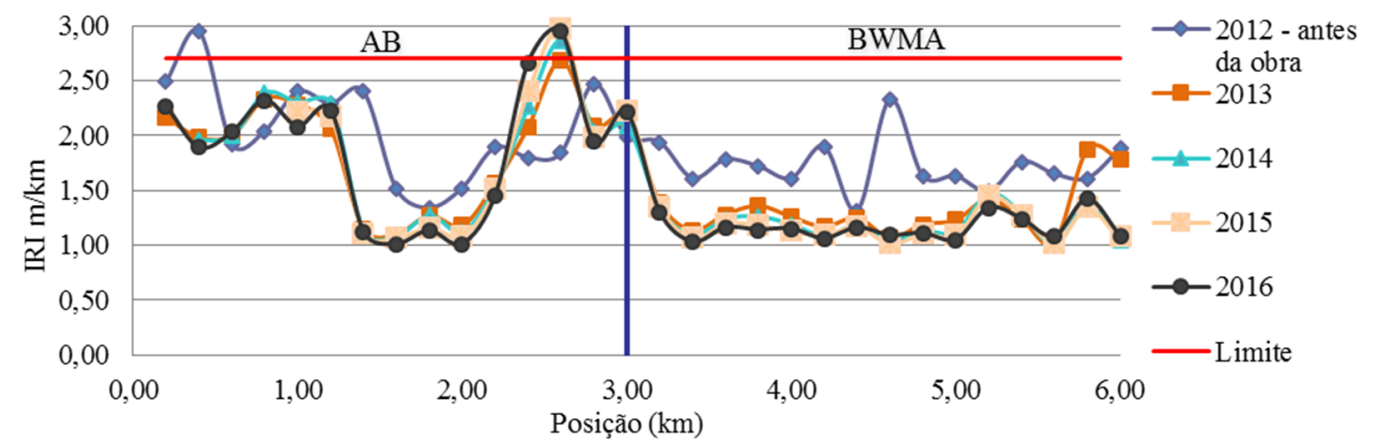

Figura 6. Resultados do levantamento de irregularidade longitudinal da faixa 02 para os anos de 2012 a 2016

Observa-se que a irregularidade longitudinal diminuiu em 2013 para o segmento da mistura BWMA e permaneceu praticamente igual entre 2014 e 2016. Tanto para o trecho AB quanto para o trecho BWMA, os resultados foram satisfatórios, ficando abaixo do limite imposto pelo edital de concessão, que é $2,7 \mathrm{~m} / \mathrm{km}$.

\subsection{Levantamento deflectométrico}

O levantamento das deflexões recuperáveis do pavimento foi realizado por meio do equipamento FWD, empregando-se uma carga de $80 \mathrm{kN}$.

Em 2009 foi realizada uma campanha de levantamento deflectométrico para elaboração do projeto. Já após a obra, em setembro de 2013 e outubro de 2016, novas medições foram realizadas para verificação estrutural do pavimento. Os valores de deflexão admissíveis foram calculados segundo as normas do DNIT, sendo elas a DNER PRO 269/94 e DNER PRO 011/79. Os resultados das medições na faixa 02 são apresentados na Figura 7.

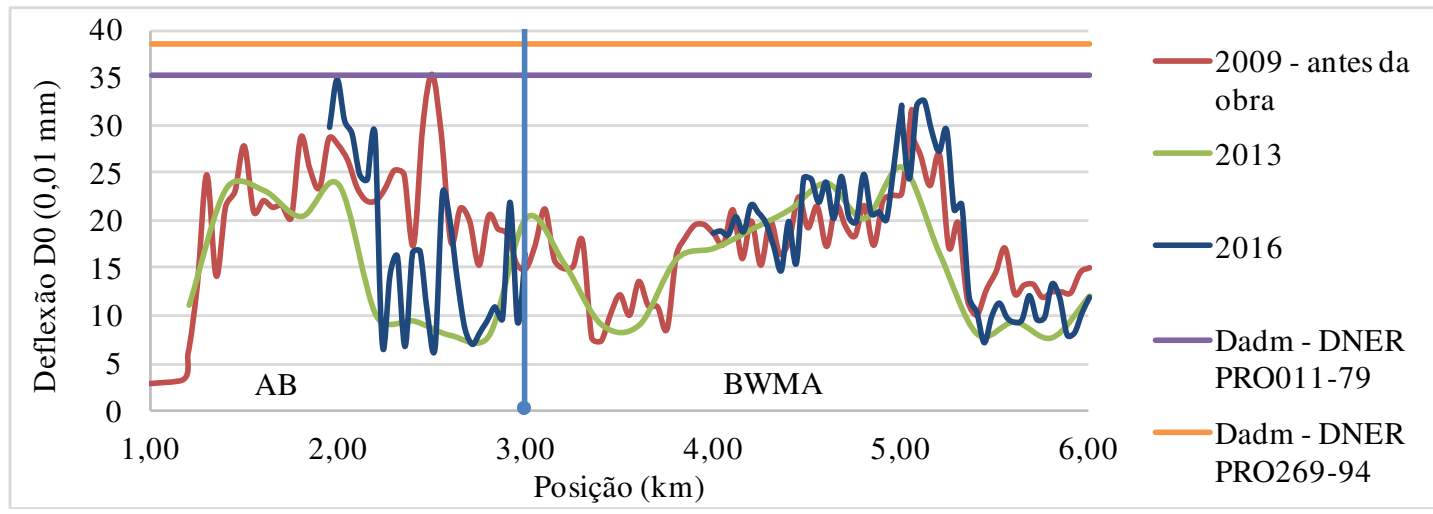

Figura 7. Resultados de deflexões com FWD realizados entre 2009 e 2016, na faixa 02 
Os valores obtidos em 2009 (antes da obra, para elaboração do projeto) e 2016, em geral, são próximos, o que indica a consolidação da estrutura do pavimento, de forma que a restauração do pavimento em 2012 teve por objetivo o atendimento de obrigação contratual e problemas funcionais, como por exemplo, envelhecimento da mistura asfáltica superficial e trincamento.

O levantamento realizado em 2013 foi feito em espaçamentos de $200 \mathrm{~m}$, o que pode ser causador da variabilidade de resultados entre os quilômetros 2+000 e 3+000. A média da deflexão em 2013 neste segmento foi de $13,5 \times 10^{-2} \mathrm{~mm}$, enquanto que em 2016 foi de $16,9 \times 10^{-2} \mathrm{~mm}$, ou seja, houve um pequeno aumento de valor. Em 2016, o levantamento foi realizado somente nos quilômetros 2+000 a 3+000 e $4+000$ a $6+000$.

O comportamento do trecho BWMA quanto aos parâmetros estruturais, até o momento da última avaliação, atendeu às expectativas esperadas para o período de serviço, apresentando deflexões abaixo do valor admissível, tanto em relação à DNER PRO 011/79 quanto à DNER PRO 269/94.

\section{DISCUSSÕES E CONCLUSÕES}

O presente trabalho foi dedicado ao acompanhamento da aplicação da mistura asfáltica morna com ligante-borracha em campo na rodovia de acesso SPA-248/055 e verificou parâmetros sustentáveis como a redução de poluentes e consumo de combustível, além de avaliar o seu comportamento em comparação com a mistura de referência, ao longo de 4 anos de serviço.

Nos ensaios laboratoriais, verificou-se que a mistura BWMA apresentou menor resistência à tração por compressão diametral, enquanto que o volume de vazios foi superior ao da mistura $A B$. Um dos possíveis motivos é a diferença na temperatura de compactação. Ambas as misturas atendem os limites de volume de vazios da faixa Gap Graded D, no entanto, AB, que foi compactada em temperatura maior, apresenta volume de vazios menor que a BWMA. Ressalta-se a relação entre a resistência à tração e o volume de vazios, ou seja, quanto menor o volume de vazios, maior a resistência à tração da mistura asfáltica.

Durante a implantação do trecho experimental, foram avaliadas as temperaturas de produção, chegada em pista e execução. A perda de temperatura em ambas as misturas foi próxima, no entanto, a utilização do aditivo surfactante permitiu trabalhabilidade e compactação da mistura asfáltica com liganteborracha em temperatura inferior, o que não seria possível sem esta tecnologia.

As medições de emissões de poluentes realizadas em usina, apresentaram redução de fumos totais e VOCs. Além do estudo de emissões, procedeu-se também com o controle de consumo de combustível GLP durante a usinagem e, assim, pode-se verificar que houve economia de combustível, em comparação à produção da mistura de referência. Esta economia é decorrente da menor temperatura de aquecimento do agregado mineral durante a produção da mistura. É importante ressaltar que os estoques de agregado estavam cobertos e protegidos de umidade excessiva.

Em geral, a mistura asfáltica morna apresentou resultados positivos quanto ao comportamento mecânico, com resultados dos ensaios dentro dos limites exigidos pela norma vigente para concreto asfáltico com borracha, de forma a ser possível afirmar que, nos parâmetros analisados, o aditivo para mistura morna não comprometeu a qualidade e desempenho do concreto asfáltico com borracha.

Considerando que as avaliações ainda são preliminares, pois a pista ainda não atingiu o período de projeto, que é de 8 anos, recomenda-se primeiramente, continuar o monitoramento do comportamento deste trecho até o final do período de projeto, a fim de verificar se a mistura atendeu seu propósito. Também é necessário avaliar o desempenho do ligante asfáltico morno com borracha no âmbito reológico e comparar seus resultados com o ligante asfalto-borracha.

Esta pesquisa foi utilizada para desenvolver a Especificação Técnica para aplicação de misturas mornas no grupo EcoRodovias, estabelecendo parâmetros de dosagem para misturas asfálticas tradicionais e também as aditivadas com polímero Estireno-Butadieno-Estireno (SBS) ou borracha, tais como: granulometria e temperaturas de usinagem. No âmbito de campo, a especificação visou estabelecer as tem- 
peraturas de aplicação e de rolagem em pista bem como os ensaios necessários para a execução de controle tecnológico da aplicação da mistura asfáltica.

\section{Agradecimentos}

Os autores agradecem ao Laboratório de Tecnologia de Pavimentação onde os ensaios desta pesquisa foram realizados e também à Ecovias/Ecorodovias, ao Engo Paulo Rosa, ao Engo Rui Klein e Engo Naélson Candido pelo convite na participação de todas as etapas da aplicação do trecho experimental.

\section{REFERÊNCIAS BIBLIOGRÁFICAS}

ASTM E 950-98. Standard Test Method for Measuring tge Longitudinal Profile of Traveled Surfaces with an Accelerometer Established Inertial Profiling Reference. West Conshohocken; 1999.

ASSOCIAÇÃO BRASILEIRA DE NORMAS TÉCNICAS. ABNT NBR 15087:2012 - Misturas asfálticas — Determinação da resistência à tração por compressão diametral. São Paulo, 2012.

BAHIA, H. U.; DAVIS, R. Effect of crumb rubber modifiers (CRM) on performance related properties of asphalt binders. Journal of the Association of Asphalt Paving Technologists. Volume 63, 1994.

BERNUCCI, L. B.; MOTTA, L. M. G. DA, CERATTI, J. A. P.; SOARES, J. B. Pavimentação asfáltica: formação básica para engenheiros. Rio de Janeiro: Petrobras - Abeda, 2010.

BONAQUIST, R. Mix design practices for warm mix Asphalt. NCHRP report 691. National Cooperative Highway Research Program. Transportation Research Board. Washington D.C, 2011.

D'ANGELO, J.; HARM, E.; BARTOSZEK, J.; BAUMGARDNER, G.; CORRIGAN, M.; COWSERT, J.; HARMAN, T.; JAMSHIDI, M.; JONES W.; NEWCOMB, D.; PROWELL B.; SINES, R.; YEATON, B. Warm mix Asphalt: European practice. National Cooperative Highway Research Program. Virginia, 2008.

DEPARTAMENTO NACIONAL DE ESTRADAS DE RODAGEM. DNER-PRO 011/79: Avaliação Estrutural dos Pavimentos Flexíveis. Rio de Janeiro, 1979. DNER-PRO 269/94: Projeto de restauração de pavimentos flexíveis - TECNAPAV. Rio de Janeiro, 1994.

DEPARTAMENTO NACIONAL DE INFRAESTRUTURA DE TRANSPORTES. DNIT 006/2003-PRO: Avaliação objetiva da superfície de pavimentos flexíveis e semi-rígidos - Procedimento. Rio de Janeiro, 2003.

DNIT 112/2009 - ES: Pavimentos flexíveis: concreto asfáltico com asfalto-borracha, via úmida, do tipo "Terminal Blending": Especificação de serviço. Rio de Janeiro, 2009.

ECOVIAS. Projeto de Reabilitação dos Pavimentos Flexíveis - RT- 22.248.000-0-P09/001 - Revisão 0. São Bernardo do Campo, 2008.

GAUDEFROY V.; VIRANAIKEN, V.; PARANHOS, R. Laboratory identification of fumes during manufacturing of hydrocarbon mixtures. In: International Society for Asphalt Pavements, Zürich. Anais... 2008.

HARRIGAN, E. T. Research Results Digest 374: A proposed technology evaluation program for warm mix asphalt. Transportation Research Board of the National Academies. Washington, D.C., 2012.

MDHS. General methods for sampling and gravimetric analysis of respirable and inhalable dust. Reino Unido (2000). Disponível em < http://www.vent-tech.co.uk/sites/vent-tech.co.uk/files/user/mdhs_14-3_general_methods_for_sampling_and_gravimetric_analysis_of_respirable_and_inhalable_dust.pdf>. Acesso em: $11 \mathrm{fev.} 2014$.

MERIGHI, C.; MAGALHAES, A.; CANDIDO, N.; MELO, D.; ROSA, P.; SUZUKI, C. Experiência da Concessionária Ecovias na utilização da tecnologia do asfalto morno com adição de borracha. In: 41a RAPv Reunião Anual de Pavimentação, 2012, Fortaleza. 41a RAPv Reunião Anual de Pavimentação, 2012.

MERIGHI, C. F. Estudo do comportamento de misturas asfálticas mornas em revestimentos de pavimento com adição de borracha moída de pneu. 201 f. Dissertação (Mestrado) - Escola Politécnica, Universidade de São Paulo, 2014.

MOTTA, R. dos S. Estudo de misturas asfálticas mornas em revestimentos de pavimentos para redução de emissão de poluentes e de consumo energético. 229 p. Tese (Doutorado) - Escola Politécnica, Universidade de São Paulo, 2011.

NIOSH 5042. Benzene-soluble fraction and total particulate (asphalt fume). Atlanta, 1998. Disponível em <http://www.cdc.gov/niosh/docs/2003-154/pdfs/5042.pdf>. Acesso em: 18 jul. 2013.

NIOSH Hazard Review. Health Effects of Occupational Exposure to Asphalt. Cincinnati, Ohio, 2000. Disponível em: <https://www.cdc.gov/niosh/docs/2001-110/pdfs/2001-110.pdf>. Acesso em: 17 jun. 2017.

NIOSH 1500: Hydrocarbons, BP 36o-126º C. Atlanta, 2003. Disponível em: <http://www.cdc.gov/niosh/docs/2003154/pdfs/1500.pdf>. Acesso em: 11 fev. 2014.

PROWELL, B. D.; HURLEY, G. C.; FRANK, B. Warm mix asphalt: Best practices. National Asphalt pavement association - NAPA. Quality Improvement Publication 125. Lanham, 2012.

RODRÍGUEZ-ALLOZA, A. M., GALLEGO, J. PÉREZ, I.; BONATI, A.; GIULIANI, F. High and low temperature properties of crumb rubber modified binders containing warm $m x$ asphalt additives. Journal Construction and Building Materials 53 - p. 460-466, 2014. http://dx.doi.org/10.1016/j.conbuildmat.2013.12.026.

RUBIO, C. R.; MARTÍNEZ, G.; BAENA, L,; MORENO, F. Warm mix asphalt: an overview. Journal of Cleaner Production 24, 76-84, 2012. https://doi.org/10.1016/j.jclepro.2011.11.053.

RUBIO, M. C.; MORENO, F.; MARTINEZ-ECHEVARRIA, M. J.; MARTINEZ, G.; VAZQUEZ, J. M. Comparative analysis of emissions from the manufacture and use of hot and half-warm mix asphalt. Journal of Cleaner Production 41- p. 1-6, 2013. https://doi.org/10.1016/j.jclepro.2012.09.036 
SABITA. Manual 32: Best practice guideline for warm mix asphalt. ISBN 978-1-8974968-55-1. South Africa, 2011.

THE ASPHALT ROOFING INDUSTRY SCIENCE \& MEDICAL GROUP. The Health Effects of Occupational Exposure to Asphalt Fumes - a review of the available scientific data and on-going industry and government research. 2000. Disponível em: < http://www.owenscorning.com/NetworkShare/Asphalt/healtheffects.pdf >. Acesso em: jul. 2014.

XIAO, F.; ZHAO, W.; AMIRKHANIAN, S. N. Fatigue Behavior of Rubberized Asphalt Concrete Mixtures Containing Warm Asphalt Additives. Construction and Building Materials v. 23, Issue 10, p. $3144-3151$, Out., 2009. Disponível em: < http://www.sciencedirect.com/science/article/pii/S0950061809001913 >. Acesso em: 15 out. 2011. https://doi.org/10.1016/j.conbuildmat.2009.06.036.

YU, X.; LENG, Z.; WEI, T. Investigation of the rheological modification mechanism of warm-mix additives on crumb-rubber modified asphalt. Journal of Materials in Civil Engineering. Volume 26, Issue 2, February, 2014. doi:10.1061/(ASCE)MT.1943-5533.0000808. 